\title{
Saúde e adoecimento psíquico de professores: estudo sobre burnoute qualidade de vida no trabalho
}

\author{
Teachers' mental health and illness: study in burnout and quality of life
}

\author{
Paula Marília de Oliveira Bispo', Carolina Villa Nova Aguiar ${ }^{2}$ \\ 'Escola Bahiana de Medicina e Saúde Pública. Salvador, Bahia, Brasil. paulabispo13.1@bahiana.edu.br \\ ${ }^{2}$ Autora para correspondência. Escola Bahiana de Medicina e Saúde Pública e na Faculdade Ruy Barbosa - DeVry. Salvador, Bahia, Brasil. \\ carolinaaguiar@bahiana.edu.br
}

Resumo I A partir do percurso histórico da carreira docente no Brasil, percebe-se que a profissão docente encontra-se inserida em um contexto de profundas contradições: por um lado, o trabalho docente é protegido por leis que pretendem garantir seu reconhecimento e as adequadas condições para o seu exercício; por outro, trata-se de um trabalho exigente e complexo, que nem sempre tem as condições de trabalho asseguradas. $O$ objetivo do presente trabalho foi identificar aspectos relacionados à saúde e ao adoecimento psíquico de professores de escolas particulares e públicas do estado da Bahia. Trata-se de uma pesquisa de caráter quantitativo e de corte transversal. Participaram do estudo 60 professores, sendo a maioria do sexo feminino $(83,3 \%)$ e pós-graduados $(69,5 \%)$. O instrumento de pesquisa contou com escalas de Burnout e de Qualidade de vida no Trabalho (QVT) validadas para o contexto brasileiro. Os procedimentos de análise envolveram estatísticas descritivas e de comparação de médias. Os resultados apontaram que $35 \%$ dos participantes manifestaram a presença da Síndrome de Burnout. Com relação à análise da QVT dos docentes, obteve-se que a média geral foi de $3,16(D P=0,66)$, o que pode ser considerado como um nível moderado. A análise conjunta dos níveis de Burnout e QVT permitiu a constatação de que professores que não apresentam a síndrome do Burnout têm uma tendência a apresentar melhor QVT. Tais achados revelam a interdependência de ambos os fenômenos. Acreditase que a presente pesquisa traz resultados capazes de contribuir com futuras intervenções realizadas junto aos professores de organizações públicas e privadas.

Palavras-chave: Síndrome de Burnout, Qualidade de Vida no Trabalho, Professores.

\begin{abstract}
From the historical trajectory of the teaching career in Brazil, it is possible to perceive that the teaching profession is inserted in a context of deep contradictions: on the one hand, the teaching work is protected by laws intended to guarantee its recognition and the adequate conditions for its exercise; on the other, it is a demanding and complex work, which does not always have the working conditions guaranteed. The objective of the present study was to identify aspects related to the mental health and illness of teachers from private and public schools in the state of Bahia. Sixty teachers participated in the study, most of them female $(83.3 \%$ ) and post-graduate $(69.5 \%)$. It is a quantitative cross-sectional study. The research used validated Burnout and Life Quality at Work (LQW) scales for the Brazilian context. The analysis procedures involved descriptive and inferential statistics. The results indicated that $35 \%$ of the participants expressed the presence of Burnout Syndrome. Regarding the analysis of teachers' $L Q W$, it was obtained that the general average was 3.16 $(S D=0.66)$, which can be considered as a moderate level. The joint analysis of the Burnout and LQW levels allowed the finding that teachers who do not present Burnout syndrome have a tendency to present better LQW. Such findings reveal the interdependence of both phenomena. It is believed that the present research brings results that are able to contribute with future interventions carried out with the teachers of public and private organizations.
\end{abstract}

Keywords: Burnout Syndrome, Quality of Life at Work, Teachers. 


\section{Introdução}

A expressão Escola Normal tem origem na palavra francesa Ecole Normale, adotada pela primeira vez pelo Padre Charles Démia, em 1672, em Lyon, para representar a concepção que a educação e a administração escolar deveriam se basear nos dogmas religiosos. No Brasil as escolas começaram a surgir no período colonial em meados do século $X V I$ e, durante muito tempo ficou sob a direção da iniciativa privada, províncias ou preceptores, que atendiam aos interesses das famílias abastadas na educação dos filhos (Castro, 2016).

Somente a partir do século XIX, com a implementação da primeira Lei Geral do Ensino na Brasil, a escola passou a ser valorizada, despertando assim o interesse da elite intelectual pela defesa da escola pública, apoiada pelo movimento abolicionista e pelos políticos liberais. Inovações pedagógicas foram implantadas e foram inseridos também novos materiais pedagógicos, como gravuras, instrumentos de ensino e mobiliários. Com o passar do tempo, a profissão que era marcada pela presença masculina, foi se tornando feminina, com a inserção das mulheres nas Escolas Normais, visto que era uma das poucas profissões aceitas a serem exercidas por mulheres pela sociedade da época. A entrada da mulher no magistério permitiu solucionar a questão do desinteresse pela profissão por parte dos homens devido à baixa remuneração (Muller, 2010).

Em 1930, Vargas criou o Ministério da Educação e quatro anos depois ele incorporou na Constituição um Plano Nacional de Educação, que sistematizou as atividades $e$ as instituições de ensino em todos os níveis, fixando os recursos a serem destinados à Educação. Nesse mesmo período, foi criada oficialmente a Primeira Escola Normal do Brasil, no Rio de Janeiro. Em seguida, outras escolas foram surgindo em anos subsequentes nos estados de Minas Gerais, Bahia e São Paulo, iniciando, assim, a discussão sobre a formação dos professores, começando pela formação dos professores primários e passando para a formação do ensino secundário e normal (Muller, 2010).

Apesar do Plano Nacional de Educação, as escolas normais brasileiras ainda tinham problemas comuns, encontrando-se entre eles: a organização da didática muito simplificada, a existência de apenas um ou dois professores para todas as disciplinas; baixa frequência e falta de interesse dos alunos; pouco investimento administrativo e na infraestrutura.

Segundo Rocha e Rocha (2014), as reformas educacionais ocorridas em 1990 - que passaram a exigir que a formação dos docentes de qualquer período escolar seja, no mínimo, o ensino superior - trouxeram, junto com elas, novas características para $\circ$ trabalho docente, como o aumento do número das tarefas a serem realizadas e uma maior responsabilização pelo desempenho dos estudantes, - que, em grande medida, é responsável pelo sentimento de frustração e, em casos extremos, pelo adoecimento desses profissionais.

Embora os aspectos mencionados por Rocha e Rocha (2014), sejam uma realidade, é preciso reconhecer que também houve avanços importantes para o exercício da docência no Brasil. Em 1996, - Ministério da Educação estabelece a Lei de Diretrizes Bases da Educação (LDB), n ${ }^{\circ}$ 9394/96 que afirma, em seu Art. 67:

que os sistemas de ensino promoverão a valorização dos profissionais da educação, assegurando-lhes, inclusive nos termos dos estatutos e dos planos de carreira do magistério público: I - ingresso exclusivamente por concurso público de provas e títulos;

II - aperfeiçoamento profissional continuado, inclusive com licenciamento periódico remunerado para esse fim; III - piso salarial profissional; IV - progressão funcional baseada na titulação ou habilitação, e na avaliação do desempenho; $V$ - período reservado a estudos, planejamento e avaliação, incluído na carga de trabalho; VI - condições adequadas de trabalho.

A partir do percurso histórico sobre a carreira docente até aqui apresentado, é possível perceber que a profissão docente encontra-se inserida em um contexto de profundas contradições: por um lado, o trabalho docente é protegido por leis que pretendem garantir seu reconhecimento e, principalmente, as adequadas condições para o seu exercício; por outro lado, é inegável que se trata de um trabalho extremamente exigente e complexo e que nem sempre as condições de trabalho necessárias para um bom desempenho são asseguradas. 
Apesar dessas contradições, a profissão docente conta, hoje, com grande reconhecimento frente à sociedade, uma vez que, indiscutivelmente, oferece relevantes contribuições. Na educação infantil e no ensino fundamental, por exemplo, os professores tornam-se fundamentais para 0 desenvolvimento psicomotor ao estimularem as crianças a desenvolverem seus aspectos cognitivos, motores, emocionais e sociais. Já no ensino médio, os professores são as principais pontes para outras profissões, visto que é nesse período que os jovens se preparam para a escolha da profissão e para entrada no mercado de trabalho.

Tendo em vista o cenário atual em que a profissão docente se encontra e, ainda, $\circ$ impacto que $\circ$ trabalho dos professores é capaz de exercer na formação dos indivíduos da sociedade em geral, pesquisas que direcionem o sev olhar para o processo de saúde e adoecimento desses profissionais tornam-se extremamente necessárias. Observase, no entanto, grande predomínio de trabalhos que focam exclusivamente no estudo de aspectos relacionados ao adoecimento do professor, sendo escassas as pesquisas que contemplem indicadores de saúde dessa categoria profissional (Carlotto, 2002). Diante disso, o presente trabalho se propõe a integrar ambas as perspectivas em um único estudo, identificando aspectos relacionados à saúde e ao adoecimento psíquico de professores dos ensinos fundamental e médio do estado da Bahia. Para isso, dois conceitos específicos do campo de estudo da saúde do trabalhador serão explorados: a Qualidade de Vida no Trabalho (QVT) e a síndrome de Burnout.

\section{Adoecimento Psíquico do Professor: Síndrome de Burnout}

Segundo Silva, Loureiro e Pares (2008) entre os aspectos da doença psíquica, a Síndrome de Burnout tem se revelado um dos que afeta mais diretamente a categoria docente. $O$ termo Burnout deriva do verbo inglês to burn out, o qual significa "queimar por completo" ou "consumir - se" e foi utilizado no campo da saúde pela primeira vez por Freudenberger para descrever uma síndrome em que a sua sintomatologia se destacava no esgotamento emocional. No Brasil, desde maio de 1996, as regulamentações da Previdência Social reconhecem a Síndrome de Burnout como um dos agentes patogênicos causadores de doenças profissionais (Andrade \& Cardoso, 2012).

De acordo com Nascimento, Sobrinho, Barros, Tironi e Marques-Filho (2010), o Burnout é uma síndrome de esgotamento profissional, decorrente da exposição contínua e excessiva a fatores interpessoais crônicos no trabalho. Três dimensões são classicamente consideradas como componentes do fenômeno: 1) exaustão emocional, que se caracteriza pela sensação de esgotamento emocional e físico no trabalho; 2) despersonalização, que se caracteriza pela adoção de atitudes frias, negativas e insensíveis, levando a um tratamento impessoal; e 3) baixa realização profissional, que se refere ao sentimento de ineficácia e impossibilidade de alcançar objetivos profissionais.

Segundo Carlotto (2002; 2007; 2011), os professores que desenvolvem a Síndrome de Burnout podem apresentar os seguintes sinais: aumento do absenteísmo, perda do entusiasmo e da criatividade, distanciamento dos alunos (redução da empatia), predisposição para $\circ$ sentimento de frustração diante de problemas ocorridos em sala de aula ou pelo progresso dos alunos, desenvolvimento de sentimentos hostis em relação a administradores $e$ familiares de alunos, desenvolvimento de percepção autodepreciativa e, ainda, arrependimentos relacionados à escolha da profissão.

As primeiras pesquisas sobre Burnout foram realizadas com predomínio em profissionais de saúde e educação, mostrando uma predisposição desses grupos para o desenvolvimento da síndrome (Benevides-Pereira, 2012). Muitas são as razões que podem ser citadas para justificar a vulnerabilidade dessa categoria profissional: devido ao baixo piso salarial, o professor passa a ser obrigado a ensinar em mais de um turno ou escola, acarretando uma sobrecarga de trabalho, prejudicando assim, seu período de descanso e lazer. A vida pessoal, as relações familiares e sociais são diretamente afetadas pela necessidade da utilização das noites e finais de semana para preparação de aulas, elaboração de provas, correção de trabalhos e avaliações. Aliado a isso, os alunos, a escola, a família e a sociedade têm cobrado cada vez mais competências do educador, já que, além dos 
conhecimentos e habilidades relacionadas à sua disciplina, espera-se que ele seja um formador em aspectos gerais como cidadania, sustentabilidade, sexualidade, relacionamento interpessoal (Andrade \& Cardoso, 2012).

Entre as pesquisas realizadas, encontra-se um levantamento realizado pela Organização Mundial da Saúde (OMS), em 2008, que apontou que a cada 100 professores da rede pública da região Centro-Oeste do Brasil, 15 sofriam da Síndrome de Burnout, predominando os sintomas: sentimento de baixa realização profissional, alto grau de esgotamento emocional e distanciamento dos alunos (Borba, Diehl, Santos, Monteiro \& Marin, 2015).

Em outro estudo envolvendo 265 professores de escolas públicas, Batista, Carlotto, Coutinho e Augusto (2011) encontraram que $33,6 \%$ dos docentes indicavam alto nível de exaustão emocional, $43,4 \%$ baixa realização profissional e $8,3 \%$ altos índices de despersonalização, trazendo repercussões na saúde mental e no desempenho profissional dos professores.

\section{Saúde Psíquica do Professor: Qualidade de Vida no Trabalho}

A Qualidade de Vida no Trabalho (QVT) passou a ser um objeto de preocupação e investimento, sobretudo nas grandes corporações, a partir da década de 1970 (Ferreira, Alves \& Tostes, 2009). Ainda de acordo com Ferreira et al. (2009), a QVT surge como um modelo teórico que favorece a discussão sobre os sentidos do trabalho - opondose às inspirações taylorista e mecanicistas de adaptação do homem ao trabalho - e propondo algumas alternativas para compatibilizar eficiência e eficácia nas organizações. Eric Trist e seus colaboradores do Tavistok Institute, em Londres, são considerados como os percussores das pesquisas ligadas à QVT (Tolfo \& Piccinini, 2001). Em seguida, outros autores também obtiveram grande destaque nesse campo de estudo, como Walton, Hackman e Oldham (Luna, Silva \& Tolfo, 2009).

Atualmente, o conceito de QVT engloba duas perspectivas interdependentes: a primeira se refere à ótica dos dirigentes e gestores, que engloba as normas, diretrizes e práticas que visam à promoção do bem-estar individual e coletivo, o desenvolvimento pessoal dos trabalhadores e $\circ$ exercício da cidadania organizacional. A segunda perspectiva, por sua vez, envolve a ótica dos trabalhadores, com as representações que estes constroem da organização na qual estão inseridos, que indicam $\circ$ predomínio de vivências de bemestar no trabalho, de reconhecimento institucional e coletivo, de possibilidade de crescimento profissional e de respeito às características individuais (Andrade \& Veiga, 2012).

Dentre os modelos teóricos existente para explicar a QVT, Walton (1973 apud Luna et al., 2009) formulou o modelo adotado com maior frequência, que contempla os princípios de humanização do trabalho e responsabilidade social das organizações. Para ele, a QVT compreende o entendimento de necessidades e aspirações do indivíduo por meio da reestruturação do desenho de cargos e novas formas de organizar o trabalho, aliadas à construção de equipes de trabalho com um maior poder de autonomia e uma melhoria do meio organizacional. O modelo citado contempla oito fatores, sendo eles: 1) compensação justa e adequada; 2) condições de trabalho; 3 ) oportunidade de uso e desenvolvimento de capacidades; 4) oportunidade de crescimento contínuo e segurança; 5) integração social no trabalho; 6) constitucionalismo; 7) trabalho e espaço total da vida; 8 ) relevância social da vida no trabalho (Silva et al., 2009).

No Brasil, Rueda et al. (2013) se propuseram a construir uma medida de QVT baseada nos pressupostos do modelo de Walton. Embora as oito dimensões previstas no modelo não tenham se confirmado empiricamente, os autores alcançaram uma solução de quatro fatores que se mostrou interpretável e adequada para a realidade brasileira. A primeira dimensão, denominada a QVT relacionada à integração, respeito e autonomia, refere-se à promoção do respeito pelas diferenças individuais e pelos direitos dos funcionários, à colaboração e respeito entre os colegas, assim como à promoção da autonomia por meio de normas e regras claras. A segunda dimensão, QVT relacionada à remuneração, envolve a satisfação com o salário e com as políticas salariais da organização. Já a terceira dimensão, QVT relacionada a possibilidades de lazer e 
convívio social, diz respeito à qualidade de convívio, proporcionadas com base em características da própria organização. Por fim, a última dimensão, QVT relacionada a incentivo e suporte, refere-se ao incentivo e suporte que a organização proporciona aos seus funcionários.

No que diz respeito especificamente à docência, Rocha e Fernandes (2008) reconhecem a necessidade de se investir na QVT desses profissionais, uma vez que apenas professores com saúde e bemestar individual estarão verdadeiramente aptos a promover o crescimento intelectual e a saúde psíquica dos seus discentes. Nota-se, portanto, que, para que seja considerada uma promotora de saúde, a escola deve investir para alcançar um quadro docente saudável física e psiquicamente.

Embora se reconheça a necessidade de investimento nesse campo, existe uma escassez de estudos na área da psicologia organizacional sobre a QVT dos docentes. Em estudo realizado por Marques, Borges e Adorno (2008) com professores de escolas públicas após a Reforma de Ensino da LDB em 1996, os achados dos autores sugerem que os professores possuem uma QVT geral classificada como moderada. Em relação às dimensões "tarefa" e "interação indivíduo-organização", os professores demonstraram satisfação moderada, sendo válido registrar que esta última dimensão apresentou diferenças significativas entre as escolas da rede estadual e municipal. Nas categorias "fatores organizacionais", "remuneração" e "atuação do governo e sindicato", os professores revelaramse insatisfeitos, sendo as duas últimas dimensões avaliadas como as maiores fontes de insatisfação. Em um estudo de caso sobre a QVT realizado com os docentes do departamento de ciências administrativas da Universidade Federal do Rio Grande do Norte (UFRN), Oliveira-Filho, Souza, Paiva, Momo e Padilha (2013) encontrou que o relacionamento interpessoal com os discentes causa prazer e satisfação enquanto a relação com outros docentes é vista como causa de insatisfação. A maioria dos docentes pesquisados demonstrou anseio por melhorias de infraestruturas.

\section{Método}

Trata-se de uma pesquisa de caráter quantitativo e de corte transversal.

\section{Participantes}

Foram convidados a participar do estudo professores de escolas públicas e privadas do estado da Bahia e a amostra final foi composta por 60 professores. Do total de participantes, a maioria é do sexo feminino $(83,3 \%)$, possui pós-graduação $(69,5 \%)$ e é casado (a) ou vive em união consensual $(58,4 \%)$. A idade dos participantes variou de 23 a 60 anos, com média de 42 anos (DP $=9,46$ ). Dentre as características organizacionais, destacase a grande concentração de escolas com menos de 100 funcionários (77,8\%). Por fim, obteve-se um equilíbrio entre escolas privadas e públicas, sendo $51,7 \%$ delas públicas.

\section{Instrumentos}

A pesquisa foi realizada através de um questionário com escalas de Burnout e de QVT previamente validadas para o contexto brasileiro.

Para mensuração do Burnout, foi utilizado o Maslach Burnout Inventory, em sua versão traduzida e adaptada para a língua portuguesa (Carlotto \& Câmara, 2007). O instrumento é composto por três dimensões: exaustão emocional ( 9 itens, $\alpha=0,85$ ); baixa realização profissional ( 8 itens, $\alpha=0,94$ ); despersonalização ( 3 itens; $\alpha=0,65$ ). Os itens da escala deveriam ser respondidos por meio de escala tipo Likert de frequência ( $1=$ nunca; $5=$ sempre).

A QVT foi avaliada através de medida proposta e validada por Rueda et al. (2013) e composta por quatro dimensões: QVT relacionada à integração, respeito e autonomia (15 itens, $a=0,89)$ QVT relacionada à compensação justa e adequada (6 itens, $\alpha=0,89)$; $Q V T$ relacionada a possibilidades de lazer e convívio social ( 6 itens, $\alpha=0,84$ ); QVT relacionada a incentivo e suporte ( 8 itens, $\alpha=0,76$ ). Os itens da escala deveriam ser respondidos por meio de escala tipo Likert de concordância ( 1 = discordo totalmente; 5 = concordo totalmente). 


\section{Procedimentos de análise}

As análises foram conduzidas com o auxílio do software Statistical Package for Social Science (SPSS). Para as análises iniciais sobre a síndrome de Burnout e a QVT, foram realizadas análises descritivas. Em seguida, foram conduzidos testes inferenciais de comparação entre médias (teste $T$ para amostras independentes) para a investigação acerca das possíveis relações estabelecidas entre os fenômenos.

\section{Questões éticas}

O presente trabalho é um recorte de um projeto maior - Traços de cultura organizacional e suas relações com a saúde e mental e adoecimento do trabalhador - aprovado pelo Comitê de Ética da Escola Bahiana de Medicina e Saúde Pública, sob o CAAE 47271315.0.0000.5544.

\section{Resultados e discussão}

Inicialmente, procurou-se descrever a manifestação da Síndrome de Burnout em professores de escolas publicas e privadas do estado da Bahia. Conforme já mencionado, a Síndrome de Burnouté considerada como uma síndrome de esgotamento profissional, proveniente da exposição prolongada a fatores interpessoais crônicos no trabalho (NascimentoSobrinho et al., 2010).

Considerando que não existe um consenso na literatura acerca da melhor forma de classificar as respostas do Maslach Burnout Inventory (instrumento adotado na presente pesquisa) julgou-se importante registrar a estratégia selecionada para a análise dos dados coletados na presente pesquisa: foram considerados como possuidores da Síndrome de Burnout aqueles professores que apresentaram nível alto em exaustão e/ou despersonalização e/ou nível baixo em realização profissional. Tal opção justifica-se pelo fato de se considerar que a manifestação de nível elevado em exaustão ou despersonalização ou de nível baixo em realização profissional já apresenta $\circ$ potencial de causar sofrimento psíquico e, consequentemente, deve ser considerado como um sinal de alarme em relação ao adoecimento no trabalho.

Na amostra pesquisada, $65 \%$ dos profissionais não apresentaram a Síndrome de Burnout enquanto os demais $35 \%$ manifestaram a presença da Síndrome. Ao comparar esses achados com dados disponibilizados pela Organização Mundial de Saúde (OMS) em 2008, de que 15\% dos professores da rede pública da região CentroOeste do Brasil sofriam da Síndrome de Burnout, é possível inferir o crescimento da manifestação da síndrome na categoria docente nos últimos anos (Borba et al., 2015). É preciso, contudo, ter cautela na interpretação de tais resultados, uma vez que é possível que os dados da OMS tenham utilizado outro parâmetro para classificação do Burnout.

Para uma análise mais detalhada, a Tabela 1 apresenta as combinações das dimensões, conforme encontrado na amostra. Como pode ser observado na tabela, 0 docente pode apresentar apenas uma dimensão da síndrome ou o acúmulo de duas dimensões, como aconteceu com a exaustão emocional e despersonalização.

Tabela 1: Combinações das dimensões do Burnout na amostra de professores

\begin{tabular}{cc}
\hline Dimensões & $\%$ \\
\hline Sem Burnout & 65,0 \\
Apenas Exaustão & 25,0 \\
Apenas despersonalização & 3,3 \\
Apenas baixa realização & 1,7 \\
Exaustão + Despersonalização & 5,0 \\
\hline
\end{tabular}

De acordo com a Tabela 1, dos $35 \%$ dos professores que apresentaram a síndrome, a maior parte manifestou elevado nível de exaustão emocional, sendo ela um sintoma isolado $(25 \%)$ ou combinado com a despersonalização $(5 \%)$. Os achados evidenciam, portanto, que essa dimensão desempenha um importante papel no adoecimento psíquico dos professores que compuseram a amostra. De acordo com Maslach et al. (2001 apud Carlotto 2011), a exaustão emocional está relacionada a uma falta ou carência de energia, entusiasmo e um sentimento de esgotamento de recursos. 
É importante registrar que os resultados do presente estudo revelaram-se divergentes quando comparados com outros estudos realizados com professores. De um modo geral, as demais pesquisas têm apontado a baixa realização profissional como a dimensão mais experienciada pelos docentes. Em estudo realizado por Batista et al. (2011), por exemplo, envolvendo 265 professores de escolas públicas, os autores apontaram que $43,4 \%$ dos docentes indicaram baixa realização profissional, $33,6 \%$ manifestaram alto nível de exaustão emocional e $8,3 \%$ altos índices de despersonalização. Da mesma forma, Carlotto (2011), ao realizar uma pesquisa com uma amostra de 881 professores de oito escolas públicas e seis escolas privadas de médio porte localizadas em Porto Alegre - RS, verificou que a dimensão com percentual mais elevado foi a de Baixa Realização Profissional (com 28,9\%) e a de menor percentual é a de Despersonalização (com $0,7 \%$ ).

Uma vez oferecida uma visão geral do Burnout na amostra de pesquisa, optou-se por explorar, de forma mais pormenorizada, cada uma das dimensões, conforme apresentado na Tabela 2. Acredita-se ser de fundamental importância atentar para aqueles docentes que apresentam níveis moderados em uma ou mais dimensões do Burnout para que medidas preventivas possam ser adotadas, de modo a evitar que o nível avance de moderado para alto. Como pode ser observado, $56,7 \%$ apresentaram um grau moderado na dimensão exaustão emocional, 53,3\% na dimensão de despersonalização e, ainda, 48,3\% em realização profissional. Nota-se, portanto, que, ainda que a maior parte dos professores não tenha sido classificada como portadora da Síndrome de Burnout, existe uma pré-disposição para que ela se manifeste.

Tabela 2: Distribuição das dimensões da Síndrome de Burnout na amostra de professores

\begin{tabular}{cccc}
\hline Dimensão & $\begin{array}{c}\text { Baixo } \\
\%\end{array}$ & $\begin{array}{c}\text { Moderado } \\
\%\end{array}$ & $\begin{array}{c}\text { Alło } \\
\%\end{array}$ \\
\hline Exaustão Emocional & 13,3 & 56,7 & 30,0 \\
Despersonalização & 38,3 & 53,3 & 8,3 \\
Realização Profissional & 1,7 & 48,3 & 5,0 \\
\hline
\end{tabular}

Partindo para a análise da qualidade de vida no trabalho (QVT) dos docentes, obteve-se que a média geral foi de 3,16 ( $D P=0,66$ ), em escala de cinco pontos (variando de 1 a 5). A Tabela 3 apresenta as médias alcançadas por cada uma das dimensões propostas por Rueda et al. (2013), assim como a média geral. Como pode ser observado, a maior média apresentada pela categoria docente pesquisada foi na dimensão relacionada à integração, respeito e harmonia $(M=3,9, D P=0,80)$, que diz respeito ao apoio dos grupos primários, igualitarismo e ausência de preconceitos. Pode-se afirmar, assim, que apesar dos desafios encontrados dentro do exercício da profissão o respeito, a integralidade e harmonia tende a prevalecer no ambiente laboral. Tal resultado vai parcialmente de encontro ao apontado por Oliveira Filho et al (2013), que, em pesquisa com os docentes do departamento de ciências administrativas da Universidade Federal do Rio Grande do Norte (UFRN), identificou que o relacionamento interpessoal com os discentes causa prazer e satisfação enquanto a relação com outros docentes é vista como causa de insatisfação.

Ainda sobre as dimensões da QVT, cabe mencionar que a dimensão relacionada à compensação justa e adequada foi a que obteve menor média $(M=2,32, D P=1,02)$, indicando a insatisfação dos professores no que se refere ao desequilíbrio entre a quantidade de trabalho e a remuneração oferecida. Tal resultado reforça achados prévios de estudos realizados anteriormente. Em pesquisa conduzida por Marques et al. (2008), por exemplo, as dimensões "fatores organizacionais", "remuneração" e "atuação do governo e sindicato" foram as responsáveis pelos menos índices de QVT, sendo as duas últimas dimensões avaliadas como as maiores fontes de insatisfação.

Tabela 3: Combinações das dimensões de QVT na amostra de professores

\begin{tabular}{lcc}
\hline \multicolumn{1}{c}{ QVT e as Dimensões } & Média & DP \\
\hline $\begin{array}{l}\text { QVT relacionada a integração, respeito } \\
\text { e harmonia }\end{array}$ & 3,91 & 0,8 \\
$\begin{array}{l}\text { QVT relacionada a compensação justa } \\
\text { e adequada }\end{array}$ & 2,32 & 1,02 \\
$\begin{array}{l}\text { QVT relacionada a possibilidade de } \\
\text { lazer e convívio social }\end{array}$ & 3,51 & 0,77 \\
$\begin{array}{l}\text { QVT relacionada a incentivo e suporte } \\
\text { geral }\end{array}$ & 2,91 & 0,66 \\
QVT geral & 3,16 & 0,66 \\
\hline
\end{tabular}


A dimensão relacionada a incentivo e suporte em geral, por sua vez, foi a que alcançou a segunda menor média $(M=2,91$, $D P=0,66)$. Aqui, é interessante notar que essa dimensão obteve $\circ$ menor desvio padrão, indicando a homogeneidade das avaliações dos docentes. Em outras palavras, pode-se dizer que há um consenso por parte dos professores em relação ao baixo incentivo e suporte recebido nessa profissão.

Um último aspecto analisado na presente pesquisa se refere à comparação dos níveis de QVT entre os professores que apresentam a síndrome de Burnout e os que não apresentam a síndrome. Com base nos achados apresentados na Tabela 4, nota-se que professores que não apresentam a síndrome do Burnout têm uma tendência a apresentar melhor QVT; da mesma forma, professores com Burnout têm, de modo geral, menor QVT. Nesse sentido, é possível inferir uma relação de estreita interdependência entre os fenômenos estudados, ainda que não seja permitido estabelecer uma relação de causa e efeito entre eles.

\begin{tabular}{|c|c|c|c|}
\hline Dimensões QVT & $\begin{array}{c}\text { Síndrome de } \\
\text { Burnout }\end{array}$ & Média & DP \\
\hline QVT relacionada a integração, respeito & Não & $4,06 * *$ & 0,70 \\
\hline e harmonia & Sim & $3,47^{* *}$ & 0,74 \\
\hline QVT relacionada a compensação justa e & Não & $2,89^{* *}$ & 1,05 \\
\hline adequada & Sim & $2,18^{* *}$ & 0,87 \\
\hline QVT relacionada a possibilidade de & Não & $3,67^{* *}$ & 0,77 \\
\hline lazer e convívio social & Sim & $3,08^{* *}$ & 0,86 \\
\hline QVT relacionada a incentivo e suporte & Não & $3,17^{* *}$ & 0,72 \\
\hline geral & Sim & $2,87^{* *}$ & 0,85 \\
\hline \multirow{2}{*}{ QVT geral } & Não & $3,45^{* *}$ & 0,63 \\
\hline & $\operatorname{Sim}$ & $2,90 * *$ & 0,65 \\
\hline
\end{tabular}

Por fim, é interessante registrar que foram encontradas diferenças significativas entre os dois grupos em todas as dimensões da QVT. Entretanto, algumas obtiveram maior destaque, como é o caso da dimensão "compensação justa e adequada", que, ainda que tenha sido responsável pelas menores médias de QVT nos dois grupos (com e sem síndrome de Burnout), foi a que apresentou a maior diferença entre eles.

\section{Considerações finais}

O campo de estudo no qual a presente pesquisa se insere tem como uma de suas características a predominância de trabalhos que enfatizam exclusivamente aspectos relacionados ao adoecimento psíquico, sendo escassas as pesquisas que consideram indicadores de saúde, em especial quando se trata do público alvo em questão: docentes (Carlotto, 2002). Diante disso, essa pesquisa se propôs a analisar aspectos relacionados à saúde e ao adoecimento psíquico de professores do estado da Bahia, integrando ambas as perspectivas em um único estudo.

Para alcançar o objetivo proposto, foram analisadas a forma como 60 docentes de escolas públicas e privadas do estado da Bahia avaliam a sua qualidade de vida no trabalho e, ainda, se experienciam o Burnout, síndrome associada ao esgotamento emocional de profissionais da área de prestação de serviços. De forma complementar, ambos os conceitos foram tratados de forma conjunta, através de testes de comparação de médias.

Os resultados apontaram para uma prevalência relativamente elevada da síndrome de Burnout 
entre os docentes estudados, o que ratifica a vulnerabilidade dessa categoria ocupacional no que diz respeito ao adoecimento psíquico. Além disso, é notável a insatisfação dessa classe em relação a alguns aspectos do seu trabalho, em especial à remuneração e ao suporte organizacional recebido, o que também corrobora para um maior sofrimento no trabalho. É importante registrar, contudo, a presença de alguns aspectos que podem ser considerados como protetores para a saúde desses docentes, como a percepção de harmonia e integração do ambiente de trabalho.

Por fim, considera-se que o presente trabalho foi capaz de apresentar uma contribuição importante para o campo em que se insere. Contudo, reconhecese a existência de algumas limitações. Entre elas, encontra-se a amostra pequena e certamente não representativa da população. Ademais, em função do reduzido número de participantes, análises comparativas entre os docentes de escolas públicas e privadas não foram possíveis. Acredita-se que tais análises poderiam explicitar importantes diferenças entre esses grupos.

Diante das limitações, recomenda-se a realização de novas pesquisas que busquem verificar a replicabilidade dos achados do presente estudo e, ainda, aprofundá-los por meio de análises mais sofisticadas. Além disso, sugere-se a condução de estudos com abordagem qualitativa, de modo que esses profissionais possam expressar melhor os seus sentimentos e emoções relativos ao seu cotidiano de trabalho.

\section{CONFLITOS DE INTERESSES}

Nenhum conflito financeiro, legal ou político envolvendo terceiros (governo, empresas e fundações privadas, etc.) foi declarado para nenhum aspecto do trabalho submetido (incluindo mas não limitandose a subvenções e financiamentos, conselho consultivo, desenho de estudo, preparação de manuscrito, análise estatística, etc).

\section{REFERÊNCIAS}

Andrade, P. S., \& Cardoso, T. A. O. (2012). Prazer e dor na docência: revisão bibliográfica sobre a Síndrome de Burnout. Saúde e Sociedade, 21(1),
1 29-1 40. Recuperado de http://www.scielo.br/ pdf/sausoc/v2 ln1/13.pdf. doi: 10.1590/S010412902012000100013

Andrade, P. P., \& Veiga, H. M. S. (2012). Avaliação dos trabalhadores acerca de um programa de qualidade de vida no trabalho: validação de escala e análise qualitativa. Psicologia: Ciência e Profissão, 32(2), 304-319. Recuperado de http://www.scielo.br/pdf/ pcp/v32n2/v32n2a04.pdf. doi:10.1590/S1414$\underline{98932012000200004}$

Batista, J. B. V., Carlotto, M. S., Coutinho, A. S., \& Augusto, L. G. S. (2011). Síndrome de Burnout: confronto entre o conhecimento médico e a realidade das fichas médicas. Psicologia em Estudo, 16(3), 429. 435. Recuperado de http://www.scielo.br/pdf/ pe/v16n3/v16n3a10.pdf. doi: 10.1590/S141373722011000300010

Benevides-Pereira, A. M. T. (2012) Considerações sobre a síndrome de burnout e seu impacto no ensino. Boletim de Psicologia, 62(137), 155-168. Recuperado de http://pepsic.bvsalud.org/pdf/bolpsi/v62n137/ v62n136a05.pdf

Borba, B. M. R, Diehl, L., Santos, A. S., Monteiro, J. K., \& Marin, A. H. (2015) Síndrome de Burnout em professores: estudo comparativo entre o ensino público e privado. Rev. Psicologia e Argumento, 33(80), 270-281. Recuperado de https://periodicos.pucpr.br/index. $\mathrm{php} /$ psicologiaargumento/article/view/20023. doi: 10.7213/psicol.argum.33.080.AO04

Carlotto, M. S. (2002). A síndrome de Burnout e o trabalho docente. Psicologia em Estudo, 7(1), 21 29. Recuperado de http://www.scielo.br/pdf/ pe/v7n1/v7n1 a03.pdf. doi: 10.1590/S141373722002000100005

Carlotto, M. S., \& Camara, S. G. (2007). Preditores da Síndrome de Burnout em professores. Psicol. esc. educ., 11 (1), 101-110. Recuperado de http://www.scielo. $\mathrm{br} / \mathrm{pdf} / \mathrm{pee} / \mathrm{v} 1 \ln 1 / \mathrm{v} 1 \ln 1$ a 10.pdf. doi: $10.1590 /$ S1413-85572007000100010

Carlotto, M. S. (2011). Fatores de risco da síndrome de burnout em técnicos de enfermagem. Rev. SBPH, 14(2), 07-26. Recuperado de http://pepsic.bvsalud. org/pdf/rsbph/v14n2/v14n2a03.pdf

Carlotto, M. S. (2011). Síndrome de Burnout em professores: prevalência e fatores associados. Psicologia: Teoria e Pesquisa, 27(4), 403-410. Recuperado de http:// www.scielo.br/pdf/ptp/v27n4/03.pdf. doi: 10.1590/ S0102-37722011000400003

Castro, M. G. B. (2016). Uma retrospectiva da formação de professores: histórias e questionamentos. Movimento Rev. Educação, 3(4), 225-245. Recuperado de 
http://www.revistamovimento.uff.br/index.php/ revistamovimento/article/view/280/309. doi: $10.22409 / \mathrm{mov} . \mathrm{v} 0 \mathrm{i} 4.280$

Ferreira, M. C., Alves, L., \& Tostes, N. (2009). Gestão de Qualidade de Vida no Trabalho (QVT) no serviço público federal: o descompasso entre problemas e práticas gerenciais. Psicologia: Teoria e Pesquisa, 25(3), 31 9-327. Recuperado de http://www.scielo. $\mathrm{br} / \mathrm{pdf} / \mathrm{ptp} / \mathrm{v} 25 \mathrm{n} 3 / \mathrm{a05v25n3.pdf.} \mathrm{doi:} \mathrm{10.1590/}$ s0102-37722009000300005

Lei de Diretrizes Bases da Educação (LDB), n 9394/96, Art. 67. Estabelece as diretrizes e bases da educação nacional. Recuperado de http://www.planalto.gov.br/ ccivil_03/leis/L9394.htm

Luna, I. N., Silva, N., \& Tolfo, S. R. (2009). Cultura Organizacional, Identidade e Qualidade de Vida no Trabalho: Articulação e Sugestões de Pesquisas em Organizações. Pesquisas e Práticas e Psicossociais, 4(1), 6-16. Recuperado de https://www.ufsj.edu.br/ portal2-repositorio/File/revistalapip/volume4_n 1 / tolfo_e_outros.pdf

Marques, A. L., Borges, R. S. G, \& Adorno, R. D. (2008). $A L D B / 96$ e a qualidade de vida no trabalho: com a palavra os docentes da rede publica de Belo Horizonte, Rev. Ciência da Administração, 10 (20), 72-94. Recuperado de https:// periodicos.ufsc.br/index.php/adm/article/ view/2175-8069.2008v1 On20p70/12675. doi: $10.5007 / 2175-8069.2008 \mathrm{v} 10 \mathrm{n} 20 \mathrm{p} 70$

Filho, S. O., Souza, W., Paiva, J., Momo, D., \& Padilha, Y. L. (2013). Qualidade de vida no trabalho: um estudo de caso com os docentes do departamento de ciências administrativas da UFRN. Revista de Administração da Unimep, 11 (3), 100-1 18. Recuperado de http://www. redalyc.org/articulo.oa?id $=273729371005$

Muller, T. M. P. (2010). A consolidação da profissão docente no Brasil: uma retrospectiva. Rev. Conhecimento e diversidade, 2(3), 90-107. Recuperado de https:// www.redib.org/recursos/Record/oai_articulo693133consolidac\%C3\%A3o-profiss \%C3\%A3o-docentebrasil-retrospectiva. doi: $10.18316 / 512$

Sobrinho, C. L. N., Barros, D. S., Tironi, M. O. S., \& Filho, E. S. M. (2010). Médicos de UTI: prevalência da Síndrome de Burnout, características sociodemográficas e condições de trabalho. Rev. bras. educ. med., 34(1), 106-1 15. http://www.scielo.br/pdf/rbem/ v34n1/a13v34n1.pdf. doi: 10.1590/S0100$\underline{55022010000100013}$

Rueda, F. J. M., Ottati, F., Pinto, L.P., Lima, T. H., \& Bueno, M. P. (2013). Construção e Validação de uma Escala de Avaliação da Qualidade de Vida no Trabalho. Avaliação Psicológica, 12 (1), 43-50. Recuperado de http://pepsic.bvsalud.org/pdf/avp/v12n1/ v12nla07.pdf

Rocha, M.C, \& Rocha, W. P. (2014). A precarização do trabalho educacional na prefeitura de Belo Horizonte: desafios para a ação sindical. Rev. Financiamento da Educação, 4(12), 1-15. Recuperado de http://seer.ufrgs.br/index.php/fineduca/article/ view $/ 66400 / 37998$

Rocha, V. M., \& Fernandes, M. H. (2008). Qualidade de vida de professores do ensino fundamental: uma perspectiva para a promoção da saúde do trabalhador. J. bras. psiquiatr. 57(1), 23-27. Recuperado de http://www.scielo.br/pdf/ibpsiq/ v57n1/v57n1 a05.pdf. doi: 10.1590/S004720852008000100005

Tolfo, S. R., \& Piccinini, V. C. (2001). As Melhores Empresas para Trabalhar no Brasil e a Qualidade de Vida no Trabalho: Disjunções entre a Teoria e a Prática. RAC, 5(1), 165-193. Recuperado de http://www.scielo.br/ $\mathrm{pdf} / \mathrm{rac} / \mathrm{v} 5 \mathrm{n} 1 / \mathrm{v} 5 \mathrm{n} 1 \mathrm{a} 10$

Silva, D. C. M., Loureiro, M. F., \& Peres, R. S. (2008). Burnout em profissionais de enfermagem no contexto hospitalar. Psicologia Hospitalar, 6(1), 39-51. Recuperado de http://pepsic.bvsalud.org/pdf/ph/ v6n1/v6nla04.pdf 